\title{
Dobutamine echocardiography and thallium-201 imaging predict functional improvement after revascularisation in severe ischaemic left ventricular dysfunction
}

\author{
R Senior, B Glenville, S Basu, B S Sridhara, E Anagnostou, R Stanbridge, \\ S J Edmondson, C E Handler, E B Raftery, A Lahiri
}

\begin{abstract}
Objectives-To evaluate the concordance between thallium-201 uptake and echocardiographic wall thickening, which are both indicators of potentially reversible myocardial dysfunction, in patients with chronic ischaemic left ventricular failure and to assess their relative contribution to predicting improvement in regional function after revascularisation in a subgroup.
\end{abstract}

Patients and methods-45 patients with chronic ischaemic left ventricular dysfunction (mean (SD) ejection fraction 25 (8)\%) underwent echocardiography before and after dobutamine infusion (10 $\mu \mathrm{g} / \mathrm{kg} / \mathrm{min})$. Of these, 22 patients underwent rest echocardiography at a mean (SD) of 9 (1) weeks after revascularisation. ${ }^{201} \mathrm{~T} 1$ imaging was performed during dobutamine echocardiography and at rest, 1 , and $4 \mathrm{~h}$ after treatment with sublingual glyceryl trinitrate on two separate days. Potentially reversible dysfunction was thought to be present when a myocardial segment contained a $\mathrm{Tl}$ score of $\geqslant 3$ (ascending score $1-4$ ), or showed improved wall thickening of a dysynergic segment during dobutamine stimulation. Results-Of the ${ }^{201} \mathrm{~T} 1$ protocols, the redistribution scan $1 \mathrm{~h}$ after treatment with glyceryl trinitrate best demonstrated myocardial viability. Concordance between ${ }^{201} \mathrm{T1}$ and dobutamine induced wall thickening was $82 \%(\kappa=0.59)$ for detecting potentially reversible myocardial dysfunction before revascularisation $(n=45)$. Regional function improved in 18 of 22 patients after revascularisation. There were 168 dysynergic segments before intervention. The sensitivity of echocardiography and ${ }^{201} \mathrm{~T} 1$ imaging for detecting "recoverable" or viable segments after revascularisation was $87 \%$ and $92 \%$ respectively and specificity was $82 \%$ and $78 \%$ respectively $(P=N S)$.

Conclusions-Dobutamine echocardiography and ${ }^{201} \mathrm{Tl}$ imaging may be used to predict mechanical improvement in dysynergic segments after revascularisation in patients with chronic ischaemic left ventricular dysfunction.

(Br Heart f 1995;74:358-364)

Keywords: dobutamine echocardiography; thallium201 imaging; chronic ischaemic left ventricular dysfunction; revascularisation
Differentiation between viable but ischaemic myocardium in patients with severe left ventricular dysfunction due to coronary heart disease, is of major clinical importance for patient management. ${ }^{1}$ It is well known that left ventricular dysfunction due to coronary artery disease increases mortality, ${ }^{2}$ and that those with a left ventricular ejection fraction of $\leqslant 25 \%$ seem to derive the greatest benefit from surgical revascularisation. ${ }^{3}$ This is presumably because patients with left ventricular dysfunction have significant amounts of viable myocardium that are "hibernating", and revascularisation results in recovery of function in these areas. Some patients, however, have left ventricular dysfunction due to predominantly scar tissue that will not recover after revascularisation, and surgical mortality is high in such patients. ${ }^{4}$ It is mandatory therefore to identify patients with potentially reversible dysfunction as these patients will derive most benefit from revascularisation. Positron emission tomography has been considered as the gold standard for the assessment of myocardial viability. ${ }^{5}$ However, the method is expensive and available only in a few centres. Accepted methods for assessing myocardial viability or potentionally reversible left ventricular dysfunction by thallium-201 imaging are mainly rest redistribution at 14-24 $\mathrm{h}$ and delayed imaging after reinjection of ${ }^{201} \mathrm{Tl}$ after exercise. ${ }^{5-7}$ Glyceryl trinitrate administered before ${ }^{201} \mathrm{Tl}$ injection has been shown to increase the delivery and uptake of ${ }^{201} \mathrm{Tl}$ in viable but severely ischaemic myocardium. ${ }^{8}$ Previous studies of glyceryl trinitrate in ischaemic heart failure have shown that significant recovery of regional wall motion abnormality may occur in patients without chest pain. ${ }^{9}$ Recent studies have also shown that cross sectional echocardiography with low dose dobutamine infusion may also uncover viable myocardium; the improved myocardial thickening of dysynergic segments is an indicator of viable myocardium, while segments with predominant "scar" tissue will not show functional improvement. ${ }^{1011}$ However, no clinical studies have simultaneously assessed the value of dobutamine echocardiography and dobutamine ${ }^{201} \mathrm{Tl}$ and rest redistribution ${ }^{201} \mathrm{Tl}$ imaging after treatment with glyceryl trinitrate to evaluate reversible myocardial dysfunction in patients with severe chronic ischaemic left ventricular failure. Therefore, the aim of the study was to assess the relative value of low dose dobutamine echocardiography and ${ }^{201} \mathrm{Tl}$ 
scintigraphy for the evaluation of potentially viable myocardium in patients with severe chronic left ventricular dysfunction and associated coronary heart disease. Furthermore, we have attempted to test the hypothesis that recovery of left ventricular function after revascularisation may be predicted by these relatively simple non-invasive tests in a subgroup of patients.

\section{Patients and methods}

SELECTION OF PATIENTS

Forty five patients were studied. Patients included in the study were those with angiographically documented coronary artery disease with left ventricular ejection fraction $<40 \%$ as assessed by cross sectional echocardiography. The functional capacity of the patients for dyspnoea was assessed according to the New York Heart Association (NYHA) classification. Patients excluded from the study were those with unstable angina, significant valvular disease, idiopathic dilated cardiomyopathy, and those who had an acute myocardial infarction within 3 months. Whenever possible, antianginal medication was withdrawn for $24 \mathrm{~h}$ before the study. This study was approved by the hospital ethical committee.

\section{STUDY DESIGN}

Basal echocardiography was performed first followed by low dose dobutamine echocardiography. ${ }^{201} \mathrm{Tl}$ was injected at the end of low dose dobutamine infusion in the first 34 patients and images were acquired within 15 min. On a separate day, a rest redistribution $\mathrm{Tl}$ study was performed at $1 \mathrm{~h}$ after pre-treatment with glyceryl trinitrate $(0.5 \mathrm{mg})$ in all patients. A further $4 \mathrm{~h}$ redistribution scan was obtained on each day. Patients undergoing revascularisation were evaluated at a mean (SD) of 9 (1) weeks later by resting echocardiography.

\section{THALLIUM IMAGING}

At the end of dobutamine infusion (10 $\mu \mathrm{g} / \mathrm{kg} / \mathrm{min}$ ) ${ }^{201} \mathrm{Tl}(74 \mathrm{MBq})$ was administered intravenously. Planar images were obtained within $15 \mathrm{~min}$ in the anterior, $45^{\circ}$ left anterior oblique, and left lateral views in the first 34 patients. As our techniques evolved and the imaging skills with single photon emission computed tomography (SPECT) improved, the last 11 patients underwent SPECT Tl imaging. Three days after dobutamine infusion a rest ${ }^{201} \mathrm{Tl}$ study was performed after pre-treatment with sublingual glyceryl trinitrate $(0.5 \mathrm{mg})$. Redistribution images were obtained at 1 and $4 \mathrm{~h}$ after injection of the tracer in the same three planar views as in the first 34 patients. The 11 patients undergoing SPECT imaging only had rest redistribution images at $1 \mathrm{~h}$ after administration of sublingual glyceryl trinitrate as analysis on the first 34 patients showed no significant difference in ${ }^{201} \mathrm{Tl}$ uptake between 1 and $4 \mathrm{~h}$ rest redistribution images. All images were obtained at the $80 \mathrm{keV}$ photo peak with $30 \%$ window and digital data were stored on a $128 \times 128$ matrix. Planar imaging was performed for 10 $\mathrm{min}$ in each view utilising a gammacamera equipped with a low energy high resolution collimator. SPECT imaging was performed in 32 projections (35 s/projection) acquired over a $180^{\circ}$ arc, from $45^{\circ}$ right anterior oblique to $45^{\circ}$ left posterior. $\mathrm{Tl}$ images were analysed semiquantitatively from each planar view, which was divided into five segments. The apex was considered as one segment, so that for each patient, a total of 13 segments were obtained. ${ }^{12}$ The SPECT images were divided into 12 segments but the reporting was similar for both $\mathrm{Tl}$ modalities. Each segment was coded as having normal (grade 1), mildly reduced (grade 2), moderately reduced (grade 3 ), or severely reduced/absent $\mathrm{Tl}$ activity (grade 4) compared with the segment with maximum uptake. For the purpose of this study, potentially reversible myocardial dysfunction was thought to be present when at least two or more contiguous segments had a $\mathrm{Tl}$ score of grade 3 or less in myocardial segments that were otherwise dysynergic by echocardiography. The images were analysed blind by two experienced observers and any difference in scoring was resolved by consensus. All images were displayed simultaneously in the unprocessed and processed modes for comparison.

\section{DOBUTAMINE ECHOCARDIOGRAPHY}

Cross sectional echocardiography was performed by commercially available wide angle phase array system (ATL, Ultramark, Bothell, Washington, USA 9, 2.5 MHz transducer). Parasternal long and short axes, apical four and two chamber views were obtained. Dobutamine was infused at a rate of 5 $\mu \mathrm{g} / \mathrm{kg} / \mathrm{min}$ followed by $10 \mu \mathrm{g} / \mathrm{kg} / \mathrm{min}$ with each dose lasting for $5 \mathrm{~min}$, under electrocardiographic and echocardiographic monitoring. Images at rest (basal), $5 \mu \mathrm{g} / \mathrm{kg} / \mathrm{min}, 10$ $\mu \mathrm{g} / \mathrm{kg} / \mathrm{min}$, and $10 \mathrm{~min}$ post-infusion were acquired and digitised on line with a $R$ wave trigger to obtain a continuous loop quad screen display using a dedicated computer system (Image View; Nova Microsonics, Mahwah, NJ, USA). Images were stored on VHS videotape, on floppy and optical disks. The left ventricle was divided into $13 \mathrm{seg}$ ments as described previously (W L Henry et al, meeting of the American Society of Echocardiography, Duke University Medical Center, North Carolina, 1982). This segmentation was based on the 20 segment model proposed by The American Society of Echocardiography, where the apex is considered as one segment. Two septal segments were assessed to match the same division for $\mathrm{Tl}$ analysis (W L Henry et al, meeting of the American Society of Echocardiography). Eight of the 13 segments were seen in at least two views, so that it improved identification of individual segments. In the 11 patients who underwent SPECT ${ }^{201} \mathrm{~T}$ ] imaging the left ventricle was divided into 12 segments to match the TI SPECT model. Each segment was assessed for wall thickening 
in a semiquantitative manner. The degree of wall thickening was graded into five categories, grade 1 being normal and grade 5 dyskinetic. Segments were considered analysable when wall thickening could be identified in at least $50 \%$ of the segments. The images were evaluated blind from the digitised quad screen display by two experienced observers. A dysynergic segment was considered to have potentially reversible dysfunction (viable) when there was an improvement in wall thickening in at least two contiguous dysynergic segments, and this was considered to be an indication of retained contractile reserve or reversible myocardial dysfunction. Differences in interpretation were resolved by consensus. ${ }^{201} \mathrm{Tl}$ scintigraphy and echocardiography were reported by two separate laboratories without knowledge of the other imaging modality. The individual matching segments were compared for final analysis.

\section{CORONARY ANGIOGRAPHY}

All patients underwent coronary arteriography in multiple projections within 2 months of the non-invasive studies. Significant coronary artery disease was identified when there was $>50 \%$ diameter stenosis in a major epicardial artery and the films were reviewed independently of the non-invasive data.

\section{REVASCULARISATION}

Patients who demonstrated potentially reversible myocardial dysfunction by dobutamine echocardiography or ${ }^{201} \mathrm{Tl}$ imaging underwent revascularisation. During revascularisation procedures an attempt was made to revascularise all major epicardial vessels with $>50 \%$ diameter stenosis independent of the demonstration of myocardial viability. The grafts were performed using intermittent cross clamp fibrillation techniques at $32.5^{\circ} \mathrm{C}$. The left internal mammary artery was used to graft the left anterior descending arteries in all patients. Of the 22 patients who had revascularisation, 18 were taking an angiotensin converting enzyme inhibitor, four a calcium channel blocker (nicardipine), and all were receiving long acting nitrates and diuretics before operation. Nitrates and calcium channel blockers were withdrawn in all patients after revascularisation.

Patients who underwent revascularisation were studied at a mean (SD) of 9 (1) weeks after intervention. Cross sectional echocardiography at rest was performed in the four views. A dysynergic segment was considered to have reversible dysfunction if it showed improvement in wall thickening. Left ventricular ejection fraction was calculated by cross sectional echocardiography utilising the apical biplanar Simpson's technique. ${ }^{13}$

\section{STATISTICAL ANALYSIS}

Data are mean (SD). Concordance and discordance between echocardiography and ${ }^{201} \mathrm{Tl}$ segments were calculated as percentages and $\kappa$ values were also calculated. Comparison between regional uptake of ${ }^{201} \mathrm{Tl}$ and dobuta- mine induced functional change was performed by $\chi^{2}$ analyses. A P value $<0.05$ was considered significant.

\section{Results}

\section{PATIENTS}

Forty five patients were investigated of whom 40 were men. The mean (SD) range age was 61 (8) (35-81) years. Thirty three patients had breathlessness as the predominant symptom and 12 also had associated angina. Seven patients were in NYHA class IV heart failure, 23 in class III, and 15 had class II symptoms. The mean (SD) (range) left ventricular ejection fraction was $25(8)(7-40) \%$. Coronary angiography revealed one, two, and three vessel disease in four, 10 , and 31 patients, respectively.

SIDE EFFECTS OF DOBUTAMINE INFUSION

None of the 45 patients who underwent low dose dobutamine infusion had any significant side effects. Eight patients complained of mild palpitation, three had mild headache, and none had dysrhythmias.

\section{DOBUTAMINE ECHOCARDIOGRAPHY AND} THALLIUM-201 IMAGING

Segments with normal wall motion at rest Of the 574 segments 299 had normal wall thickening at rest. All segments showed increased contractility at peak dose of dobutamine $(10 \mu \mathrm{g} / \mathrm{kg} / \mathrm{min})$, a normal response to an inotropic agent. These segments also showed normal ${ }^{201} \mathrm{Tl}$ uptake in the redistribution images after administration of glyceryl trinitrate at rest, suggesting excellent concordance for normality.

\section{Dysynergic segments at rest}

In the first 34 patients there were 207 dysynergic segments, of which 143 improved with dobutamine echocardiography. Of these 143 segments, rest redistribution ${ }^{201} \mathrm{Tl}$ imaging showed tracer uptake in $131(92 \%)$ segments at $1 \mathrm{~h}$ and $120(84 \%)$ at $4 \mathrm{~h}$ after glyceryl trinitrate administration, suggesting superiority of the $1 \mathrm{~h} \mathrm{imaging} \mathrm{time.} \mathrm{By} \mathrm{contrast,}$ uptake of ${ }^{201} \mathrm{Tl}$ occurred in 129 segments (90\%) with dobutamine $\mathrm{Tl}$ imaging - that is, less than rest redistribution imaging at $1 \mathrm{~h}$ after glyceryl trinitrate administration. Therefore, we used the $1 \mathrm{~h}$ time point for comparison between ${ }^{201} \mathrm{Tl}$ imaging and echocardiography for the 45 patients studied here. Concordance between dobutamine echocardiography and rest redistribution ${ }^{201} \mathrm{Tl}$ imaging at $1 \mathrm{~h}$ after glyceryl trinitrate administration was better $(81 \%, \kappa=0.51)$ than between dobutamine echocardiography and dobutamine $\mathrm{Tl}$ imaging $(75 \%, \kappa=0.47)$

In 45 patients 275 segments (48\%) were dysynergic at rest, of which 179 (65\%) showed improved wall thickening with dobutamine. Of these 179 segments, 172 (96\%) showed significant tracer uptake by rest redistribution ${ }^{201} \mathrm{Tl}$ imaging at $1 \mathrm{~h}$ after glyceryl trinitrate administration. Ninety six segments did not improve during dobutamine infusion. 
Table 1 Comparison between dobutamine echocardiography and rest redistribution thallium-201 imaging at $1 \mathrm{~h}$ after treatment with glyceryl trinitrate (201 Tl imaging) for identification of reversible and nonreversible dysynergic segments before revascularisation

\begin{tabular}{lcl}
\hline & ${ }^{201}$ Tl imaging & \\
& Viable & Non-viable \\
\hline Dobutamine echocardiography & & \\
Viable & 165 & 14 \\
Non-viable & 35 & 61 \\
\hline
\end{tabular}

Concordance $=82 \% ; \kappa=0.59 ;$ Viable, reversible dysfunction non-viable, non-reversible dysfunction.

However, ${ }^{201} \mathrm{Tl}$ uptake of at least grade 3 or less was present in $35(36 \%)$ of these 96 segments by rest redistribution ${ }^{201} \mathrm{Tl}$ imaging at $1 \mathrm{~h}$ after glyceryl trinitrate administration.

An interesting phenomenon was noted when ${ }^{201} \mathrm{Tl}$ images were performed simultaneously with echocardiography after infusion of low dose dobutamine. A defect in ${ }^{201} \mathrm{Tl}$ perfusion was observed in 14 segments (three patients) where, in contrast, wall thickening improved with dobutamine (discordance). When ${ }^{201} \mathrm{Tl}$ was reinjected at rest and after pre-treatment with sublingual glyceryl trinitrate, however, 10 of the 14 segments showed normalisation or improvement in regional perfusion.

There was a good concordance of $82 \%$ $(\kappa=0.59)$ between dobutamine echocardiography and rest redistribution ${ }^{201} \mathrm{Tl}$ imaging at $1 \mathrm{~h}$ after glyceryl trinitrate administration for detecting potentially reversible dysfunction and non-reversible dysfunction in the 275 dysynergic segments (table 1 ).

\section{Post-revascularisation}

Revascularisation was performed in 22 patients (21 men of mean (SD) age 61 (12) years) at a mean (SD) of 14 (2) weeks after imaging at the time of this analysis (table 2). Three patients were in class IV heart failure, 14 in class III and five in class II heart failure. All five patients in class II had angina as the predominant symptom. Fourteen patients had three vessel disease, five two vessel disease and three severe proximal stenosis of the left

Table 2 Patient characteristics in the revascularised group

\begin{tabular}{|c|c|c|c|c|c|c|c|c|}
\hline No & Sex & $\begin{array}{l}\text { Age } \\
\text { (years) }\end{array}$ & $\begin{array}{l}\text { Functional } \\
\text { class } \\
(N Y H A)\end{array}$ & $\begin{array}{l}L A D \\
(\%)\end{array}$ & $\begin{array}{l}L C A \\
(\%)\end{array}$ & $\begin{array}{l}R C A \\
(\%)\end{array}$ & $\begin{array}{l}E F \\
(\%)\end{array}$ & $\operatorname{Rev}$ \\
\hline 1 & M & 81 & 4 & $>90$ & 100 & 100 & 23 & CABG \\
\hline 2 & $\mathbf{M}$ & 65 & 3 & $>90$ & 80 & 50 & 16 & CABG \\
\hline 3 & $M$ & 67 & 3 & $>90$ & 80 & 50 & 7 & CABG \\
\hline 4 & $M$ & 70 & 3 & 80 & 100 & 70 & 17 & CABG \\
\hline 5 & $M$ & 67 & 3 & 90 & 90 & 100 & 35 & CABG \\
\hline 6 & M & 35 & 2 & $>90$ & 0 & 0 & 35 & PTCA \\
\hline 7 & $M$ & 46 & 2 & 100 & 0 & 0 & 33 & PTCA \\
\hline 8 & M & 70 & 4 & $>90$ & 80 & 80 & 25 & CABG \\
\hline 9 & M & 45 & 3 & $>90$ & 70 & 0 & 19 & CABG \\
\hline 10 & M & 68 & 3 & 90 & 90 & 80 & 25 & CABG \\
\hline 11 & $M$ & 60 & 3 & 100 & 70 & 0 & 34 & CABG \\
\hline 12 & $M$ & 58 & 2 & 90 & 90 & 0 & 26 & CABG \\
\hline 13 & M & 68 & 3 & 100 & 80 & 60 & 39 & CABG \\
\hline 14 & $M$ & 65 & 2 & 100 & 95 & 100 & 24 & CABG \\
\hline 15 & M & 70 & 3 & 100 & 100 & 0 & 22 & CABG \\
\hline 16 & M & 49 & 3 & 100 & 100 & 0 & 34 & CABG \\
\hline 17 & $\mathrm{~F}$ & 65 & 3 & 100 & 70 & 70 & 34 & CABG \\
\hline 18 & M & 53 & 4 & 100 & 80 & 80 & 19 & CABG \\
\hline 19 & $M$ & 73 & 2 & 100 & 0 & 0 & 38 & PTCA \\
\hline 20 & $\mathrm{M}$ & 75 & 3 & 100 & 100 & 90 & 32 & CABG \\
\hline 21 & $M$ & 52 & 3 & 100 & 100 & 80 & 23 & CABG \\
\hline 22 & M & 43 & 3 & 99 & 100 & 100 & 26 & CABG \\
\hline
\end{tabular}

$\mathrm{EF}$, left ventricular ejection fraction; $\mathrm{LAD}$, left anterior descending artery; LCA, left circumflex artery; NYHA, New York Heart Association; RCA, right coronary artery; Rev, revascularisation. anterior descending arteries. Mean (SD) (range) left ventricular ejection fraction was 26 (8) (7-39)\%. Nineteen patients underwent coronary artery bypass grafting (at least two vessels) and three had coronary angioplasty for left anterior descending coronary disease. Rest echocardiography was performed at a mean (SD) of 9 (1) weeks after revascularisation. None had clinical evidence of perioperative or post-angioplasty myocardial infarction or restenosis at the time of investigation.

Echocardiography in the 22 patients who had revascularisation showed 168 dysynergic segments before intervention and $118(70 \%)$ improved after revascularisation. Table 3 gives the true positive/negative and false positive/negative values for both imaging modalities. Table 4 gives the sensitivity, specificity, and positive and negative predictive values for determining recovery of segments post-revascularisation for each imaging modality.

There was a concordance of $84 \%$ $(\kappa=0.63)$ between dobutamine echocardiography and ${ }^{201} \mathrm{Tl}$ imaging for detecting reversible and non-reversible myocardial dysfunction (table 5).

We have also assessed the combined strength of the two imaging techniques for detection of potentially recoverable dysfunction. A positive finding was thought to be present when the two methods were combined when either method was positive, however, a lack of viability was thought to be present when both methods were negative. The com-

Table 3 Comparison between dobutamine echocardiography and thallium-201 imaging at $1 \mathrm{~h}$ after treatment with glyceryl trinitrate ( ${ }^{01}$ Tl imaging) for identification of reversible dysynergic segments after revascularisation

\begin{tabular}{llc}
\hline Segments $^{*}$ & $\begin{array}{l}\text { Dobutamine } \\
\text { echocardiography }\end{array}$ & ${ }^{20 I}$ Tl imaging \\
\hline True positive & $103(87)$ & $108(92)$ \\
True negative & $41(82)$ & $39(78)$ \\
False posive & $9(18)$ & $11(33)$ \\
Flase negative & $15(13)$ & $10(8)$ \\
\hline
\end{tabular}

${ }^{\star}$ Values in parenthesis are percentages. Wall thickening improved after revascularisation in 118 segments but not in 50 improved

Table 4 Sensitivity, specificity, and predictive value of dobutamine echocardiography and thallium-201 imaging at $1 \mathrm{~h}$ after treatment with glyceryl trinitrate ${ }^{201} \mathrm{Tl}$ imaging) in identifying reversible myocardial dysfunction

\begin{tabular}{lll}
\hline & ${ }^{201}$ Tl imaging & $\begin{array}{l}\text { Dobutamine } \\
\text { echocardiography }\end{array}$ \\
\hline Sensitivity (\%) & 92 & 87 \\
Specificity (\%) & 78 & 82 \\
Positive predictive value & 91 & 92 \\
Negative predictive & 79 & 73 \\
$\quad$ value (\%) & 79 & \\
\hline
\end{tabular}

Table 5 Comparison between dobutamine echocardiography and thallium-201 imaging at $1 \mathrm{~h}$ after treatment with glyceryl trinitrate ( ${ }^{01} \mathrm{Tl}$ imaging) for identification of reversible and non-reversible dysynergic segments after revascularisation

\begin{tabular}{lll}
\hline & ${ }^{20}$ Tl imaging & \\
\cline { 2 - 3 } & Viable & Non-viable \\
\hline Echocardiography & & \\
Viable & 102 & 10 \\
Non-viable & 17 & 39 \\
\hline
\end{tabular}

Abbreviations as in table 1 . 

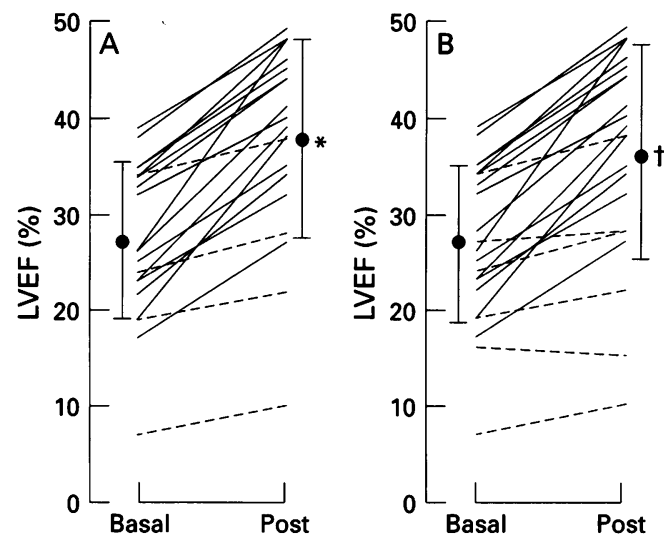

Figure 1 Left ventricular ejection fraction (LVEF) at rest (basal) and after revascularisation (post). (A) Patients with improved wall thickening in two or more contiguous segments as demonstrated by dobutamine echocardiography. (B) Patients with at least grade 3 thallium-201 uptake in two or more contiguous segments before surgery; - patients with $>5 \%$ improvement in bVere surgery; - , patients with $>5 \%$ improvement improvement in ejection fraction $<5 \%$ after

revascularisation. Error bars show the mean (SD).

${ }^{\star} P<0.001 ;+P<0.005$, paired $t$ test.

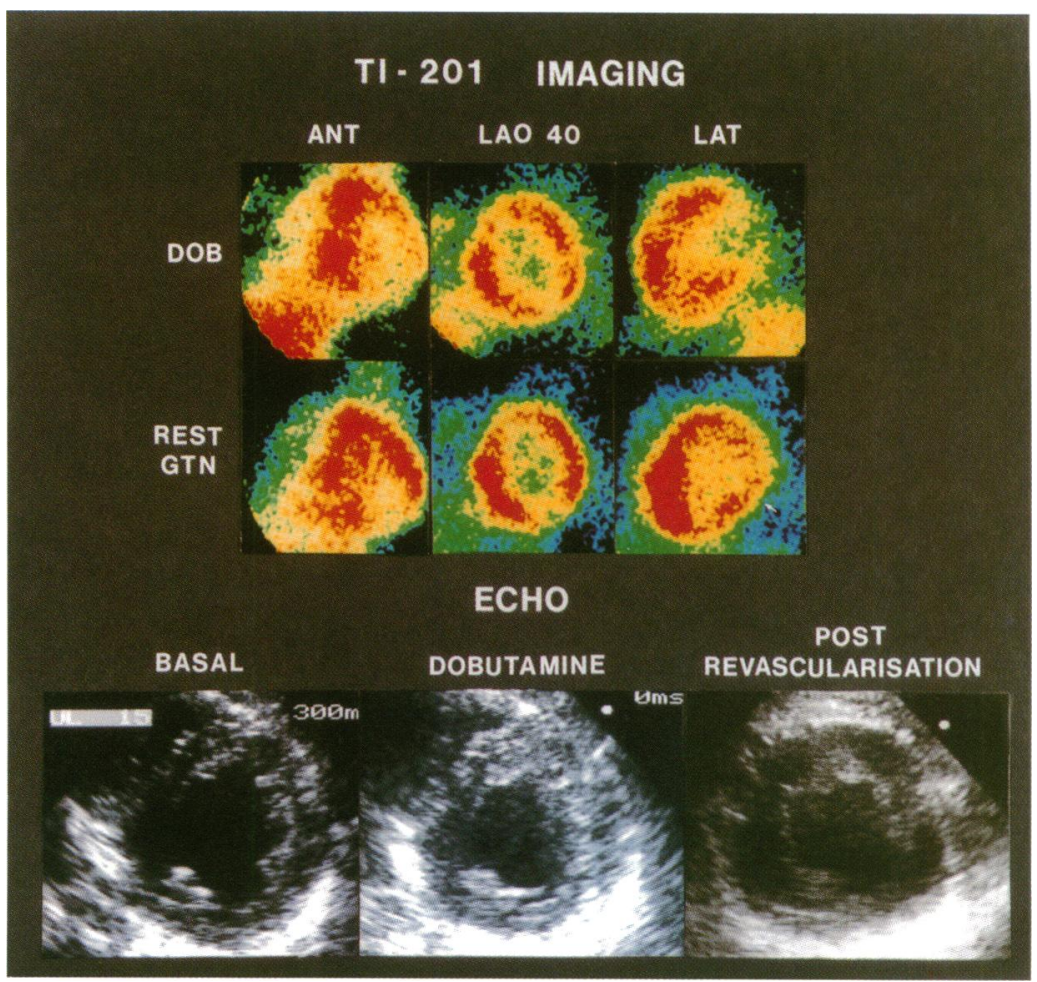

Figure 2 Composite image of a patient with a preoperative ejection fraction of $17 \%$, three vessel disease, and New York Heart Association class IV congestive heart failure. The top panels of dobutamine and rest redistribution thallium-201 imaging at $1 \mathrm{~h}$ after treatment with glyceryl trinitrate show enhanced regions of ${ }^{201} T 7$ uptake in the anterior, septal, and lateral walls. The lower panel shows echocardiographic images at rest (basal) and low dose dobutamine before surgery and at rest after revascularisation (bottom right). All echocardiographic images are in the short axis at end systole. The basal echocardiogram shows discordance, as there is severe global hypokinesia, but the ${ }^{201} \mathrm{Tl}$ image after treatmen with glyceryl trinitrate shows significant uptake in the anteroseptal and lateral walls. The dobutamine echocardiogram shows improved wall thickening in the anteroseptal, lateral, and inferior walls (ejection fraction 30\%), but not in the inferoposterolateral wall, which shows a matching perfusion defect in the same region with ${ }^{201} \mathrm{Tl}$ imaging. After revascularisation the segments which show improved contractility are the antero-septal and lateral walls, which were predicted by ${ }^{201} \mathrm{Tl}$ and dobutamine echocardiography. There was no improvement in the inferoposterolateral wall, which was also predicted. The ejection fraction improved to $32 \%$. Note reduced anterolateral perfusion on ${ }^{201} \mathrm{Tl}$ imaging during dobutamine infusion despite increased contractility as demonstrated by echocardiography in the same region. Echo, cross sectional echocardiography; GTN, Glyceryl trinitrate; ${ }^{201} \mathrm{Tl}$, Thallium-201 imaging; DOB, dobutamine; ANT, anterior; LAO 40, left anterior oblique, $L A T$, lateral. bined approach gave a sensitivity of $97 \%$ and a specificity of $78 \%$. There was no significant difference between sensitivity and specificity obtained by combining the results of two tests compared with those of either test alone.

Of the 22 patients who were revascularised, 18 showed improvement in wall thickening in at least two contiguous dysynergic segments and four patients showed no improvement. Of the 18 who showed an increase in wall thickening, 16 had an improvement in left ventricular ejection fraction by at least $5 \%$, while two showed no improvement. Dobutamine echocardiography before revascularisation correctly predicted improvement in the 18 patients who demonstrated improvement in regional function; however, this technique falsely predicted improvement in two of the four patients who did not show any improvement after surgery. Figure 1 shows the changes in left ventricular ejection before and after revascularisation in the 20 patients who showed regional improvement with dobutamine echocardiography. Mean (SD) left ventricular ejection fraction improved from $27(8) \%$ to $38(9) \% \quad(P<0.001)$. Sixteen patients who showed improvement in left ventricular ejection fraction postoperatively also showed improvement by at least one functional class.

Preoperative ${ }^{201} \mathrm{Tl}$ imaging (rest redistribution at $1 \mathrm{~h}$ after glyceryl trinitrate administration) predicted the presence of potentially reversible dysfunction in the 22 patients who had revascularisation. Figure 1 shows the changes in left ventricular ejection fraction before and after revascularisation in the 22 patients considered to have viable or reversible dysfunction by ${ }^{201} \mathrm{Tl}$ imaging. Sixteen of these patients showed improvement by $5 \%$ in left ventricular ejection fraction; mean (SD) ejection fraction improved from $26(8)$ to $36(8)(P<0.005)$. Figure 2 shows an example of a patient with the combined imaging modalities.

\section{Discussion}

Previous studies have shown that reversal of wall motion abnormalities with inotropic stimulation or glyceryl trinitrate predicts recovery of left ventricular function after revascularisation. ${ }^{14-17}$ This information is particularly relevant in patients with severely compromised left ventricular function who are being considered for revascularisation. Although such patients have significantly higher surgical morbidity and mortality, their long-term survival is improved with coronary bypass surgery compared with that of medical treatment. ${ }^{3}$ It has been shown by Nesto et $a l^{14}$ that patients with depressed left ventricular function who demonstrate significant improvement in left ventricular ejection fraction during inotropic stimulation have improved left ventricular function and better long-term survival after coronary revascularisation. By contrast, comparable patients lacking contractile reserve have a poor prognosis whether treated medically or surgically. ${ }^{14}$

Dobutamine, in low doses, has been shown 
to improve contractile response in myocardial segments that are dysynergic at rest, thus demonstrating contractile reserve. ${ }^{18}$ Previous studies have shown that low dose dobutamine echocardiography can identify contractile reserve in the setting of acute myocardial infarction ${ }^{11}$ and also in patients with chronic ischaemic left ventricular dysfunction. ${ }^{1920}$ Our results confirm the findings of Cigarroa et al ${ }^{19}$ and Marzullo et $a^{20}$ that detection of contractile reserve by low dose dobutamine echocardiography is a good predictor of recovery of left ventricular function after coronary revascularisation. The population of patients evaluated in our study had a mean left ventricular ejection fraction of $25 \%$, which was considerably lower than that of the previous two studies mentioned and 18 of 22 patients who underwent revascularisation showed improved contractile reserve as predicted by dobutamine echocardiography. This indicates the value of low dose dobutamine echocardiography for identification of patients with severe left ventricular dysfunction who are likely to improve after revascularisation. Two of the 18 patients who showed contractile reserve, however, did not show any appreciable improvement in left ventricular ejection fraction nor a change in functional class after revascularisation.

Both ${ }^{201} \mathrm{Tl}$ reinjection and delayed imaging have identified potentially recoverable left ventricular function after revascularisation. ${ }^{21-23}$ Dilsizian $e t ~ a l^{24}$ recently compared rest redistribution with stress redistribution reinjection ${ }^{201} \mathrm{Tl}$ protocols showing that both provide concordant information regarding viability. Glyceryl trinitrate has been shown to increase the delivery and uptake of ${ }^{201} \mathrm{Tl}$ in viable but severely ischaemic myocardium. ${ }^{8}$ In this study, we have assessed the value of ${ }^{201} \mathrm{Tl}$ imaging at $1 \mathrm{~h}$ and $4 \mathrm{~h}$ after administration of sublingual glyceryl trinitrate $(500 \mu \mathrm{g})$ at rest and during dobutamine infusion. There was no significant difference in the results between the three imaging modalities; however, the largest number of potentially viable segments was detected when imaging was performed $1 \mathrm{~h}$ after pre-treatment with glyceryl trinitrate. ${ }^{25}$ Thus, it seems that the best imaging time after treatment with glyceryl trinitrate is $1 \mathrm{~h}$ postinjection of ${ }^{201} \mathrm{Tl}$, and in fact, further delay in imaging produces a reduction in sensitivity for detecting potentially viable myocardium.

The accuracy of rest ${ }^{201} \mathrm{Tl}$ imaging after glyceryl trinitrate administration for predicting improvement of wall thickening after revascularisation was similar to low dose dobutamine echocardiography (concordance $84 \%$ ). Our results showed similar predictive accuracy to the study of Marzullo et $a l^{20}$ for identifying viable myocardium in patients with ischaemic left ventricular dysfunction. They utilised a $14 \mathrm{~h}$ delayed imaging protocol after ${ }^{201} \mathrm{Tl}$ injection and assessed uptake quantitatively. Picano et $a l$ reported good correlation between quantitative and qualitative ${ }^{201} \mathrm{Tl}$ analysis in patients with ischaemic left ventricular dysfunction.

In our study, four of the 22 patients who were considered to have appreciable ${ }^{201} \mathrm{Tl}$ uptake in the dysynergic segments did not show improvement in contractile function post-revascularisation. Quantitative analysis and tomographic study could possibly have given better categorisation of these segments, but it is also possible that metabolic activity and myocardial perfusion may be present in the absence of contractile function, with the existence of small islands of viable myocytes in a predominantly infarcted region that is incapable of contractile improvement after revascularisation. ${ }^{26}$ We have demonstrated a lack of significant improvement in the detection of reversible myocardial dysfunction by combining both methods. This may be explained by the relatively small number of segments for the calculation of synergistic effect using both techniques.

Both these techniques individually have been shown to be indicators of viable myocardium. ${ }^{2023}$ We have demonstrated in a relatively large number of myocardial segments that dobutamine echocardiography and rest redistribution ${ }^{201} \mathrm{Tl}$ imaging at $1 \mathrm{~h}$ after treatment with glyceryl trinitrate have a high degree of concordance $(81 \%, \kappa=0.51)$ for the identification of potentially reversible myocardial dysfunction. Although ${ }^{201} \mathrm{Tl}$ identified a slightly larger number of segments as viable compared with that of echocardiography there was no significant difference. In this study, we had the opportunity of comparing low dose dobutamine echocardiography and dobutamine ${ }^{201} \mathrm{Tl}$, and it seems that dobutamine ${ }^{201} \mathrm{Tl}$ is an unsuitable technique for identifying myocardial viability.

Positron emission tomography has been considered as the gold standard for assessment of viable myocardium, and this has been compared with ${ }^{201} \mathrm{Tl}$ imaging ${ }^{5}$ and low dose dobutamine echocardiography. ${ }^{10}$ However, this method is expensive and available only in a few centres, which limits its application. Recently, technetium- 99 m sestamibi, a relatively new myocardial perfusion agent, has been found to have a good diagnostic potential for detection of reversible myocardial dysfunction..$^{27}$ However, further larger scale studies are required in this class of patients.

We have found an interesting dichotomy that requires further explanation. During dobutamine infusion 14 segments (in three patients) revealed ${ }^{201} \mathrm{Tl}$ defects despite increasing wall thickening. This occurred in regions supplied by a severely stenotic artery and rest ${ }^{201} \mathrm{Tl}$ imaging (after treatment with glyceryl trinitrate) showed improvement in regional perfusion in 10 of these segments. The possible explanation may be that dobutamine even at such a low dose produces myocardial ischaemia, and this may be suggestive of severely compromised coronary flow reserve. If the dose of inotrope had been increased then wall thickening would consequently have been reduced. This finding may suggest a more urgent need for revascularisation in this group of patients as the myocardium has a very low coronary flow reserve and is therefore likely to progress to irreversible damage. ${ }^{29}$ 
LIMITATIONS OF THE STUDY

The first limitation stems from the inherent approximation resulting from direct comparison of myocardial segments imaged by two different techniques. We tried to minimise this problem by using a matching segmental model for both imaging modalities. Echocardiography may not be feasible in $5-10 \%$ of patients because of technically inadequate images. In addition, paradoxical septal motion may confound the interpretation of regional left ventricular function after bypass surgery. We have therefore, emphasised systolic wall thickening and not wall motion as the gold standard, which minimises the errors. ${ }^{30}$ Although we have evaluated left ventricular ejection fraction and functional class as parameters for assessing the contribution of the two techniques for identifying reversible myocardial dysfunction, we feel that long-term survival analysis will be the ultimate marker for application of these tests.

\section{Conclusion}

In patients with severe chronic left ventricular dysfunction due to ischaemic heart disease, low dose dobutamine echocardiography and ${ }^{201} \mathrm{Tl}$ imaging at $1 \mathrm{~h}$ after treatment with glyceryl trinitrate have good potential for detecting reversible myocardial dysfunction and predicting recovery of regional left ventricular function after revascularisation. The cost of both techniques is similar. If both methods are available then individual expertise in either technique will ultimately determine the method of choice.

The authors thank Usha Raval for technical assistance.

1 Brundage $\mathrm{BH}$, Massie $\mathrm{BM}$, Botvinick $\mathrm{EH}$. Improved regional ventricular function after successful surgical revascularization. $₹ \mathrm{Am}$ Coll Cardiol 1984;3:902-8.

2 Lee KL, Pryor DB, Peiper KS, et al. Prognostic value of radionuclide angiography in medically treated patients with coronary artery disease. A comparison with clinical with coronary artery disease. A comparison with clinical
and catheterisation variables. Circulation 1990;82: and cathe $1705-17$.

3 Alderman EL, Fisher KD, Litwin P, et al. Results of coronary artery surgery in patients with poor left ventricular function (CASS). Circulation 1983;68:785-95.

4 Kirklin JW, Naftel DC, Blackstone EH, Pohost GM. Summary of a consensus concerning death and ischaemic events after coronary artery bypass grafting. Circulation 1989;79(suppl 1):I81-91.

5 Bonow RD, Dilsizian V, Cucolo A, Bacharach SL Identification of viable myocardium in patients with chronic coronary artery disease and left ventricular dysfunction: comparing thallium scintigraphy with reinjection and PET imaging with $18 \mathrm{~F}$-fluorodeoxyglucose. Circulation 1991;83:26-37.

6 Kiat H, Berman DS, Maddahi J, et al. Late reversibility of tomographic myocardial thallium-201 defects: an accurate marker of my

7 Picano E, Marzullo P, Gigli G, et al. Identification of viable myocardium by dipyridamole-induced improvement in regional left ventricular function assessed by echocardiography in myocardial infarction and comparison with thallium scintigraphy at rest. $A m \mathcal{F}$ Cardio 1992;70:703-10

8 He Z, Darcourt J, Guignier A, et al. Nitrates improve detection of ischemic but viable myocardium by thallium-201 reinjection SPECT. F Nucl Med 1993;34: 1472-7.

9 Lahiri A, Crawley JCW, Sonecha TN, Raftery EB. Acute and chronic effects of sustained action buccal nitroglyc- erin in severe congestive heart failure. Int $f$ Cardiol $1984 ; 5: 39-48$

10 Pierard LA, De Landsheere CM, Berthe C, Rigo P, Kulbertus HE. Identification of viable myocardium by echocardiography during dobutamine infusion and positron emission tomography. $₹$ Am Coll Cardiol 1990;15:1021-31.

11 Barilla F, Gheorghiade M, Moshin A, Khaja F, Goldstein S. Low dose dobutamine in patients with acute myocardial infarction identifies viable but not contractile myocardium and predicts the magnitude of improvement in wall motion abnormalities in response to coroment in wall motion abnormalities in response to coro-
nary revascularisation. Am Heart $\mathcal{F} 1991 ; 122: 1522-31$.

12 Silvermann KJ, Becker LC, Bulkley BH. Value of early thallium-201 scintigraphy for predicting mortality in thallium-201 scintigraphy for predicting mortality in patients with acute

13 Folland ED, Parisi AF, Moynihann PF, Jones DR, Feldman CL, Tow DE. Assessment of left ventricular ejection fraction and volumes by real-time, two dimensional echocardiography: a comparison of cineangiographic and radionuclide techniques. Circulation 1979;60:760-6.

14 Nesto RW, Cohn LH, Collins J, Wynne J, Holman L, Cohn PF. Inotropic contractile reserve: a useful predictor of increased 5 year survival and improved postoperative left ventricular function in patients with coronary artery disease and reduced ejection fraction. Am $\mathcal{f}$ Cardiol 1982;50:39-44.

15 Helfant RH, Pine R, Meister SG, Feldman MS, Trout Helfant RH, Pine R, Meister SG, Feldman MS, Trout
RG, Banka VS. Nitroglycerin to unmask reversible RG, Banka VS. Nitroglycerin to unmask reversible asynergy: correlation with post coronary
culography. Circulation 1974;50:108-13.

16 Popio KA, Gorlin R, Bechtel D, Levine JA. Postextrasystolic potentiation as a predictor of potential myocardial viability: pre-operative analyses compared with studies after coronary bypass surgery. $\mathrm{Am} \mathcal{F}$ Cardiol 1977;39:944-51.

17 Horn HR, Tiecholz LE, Cohn PF, Herman MV, Gorlin R Augmentation of left ventricular contraction pattern in coronary artery disease by an inotropic catecholamine: the epinephrine ventriculogram. Circulation $1974 ; 49$ : 1063-71.

18 Schulz R, Guth BD, Pieper K, Martin C, Heusch G. Recruitment of an inotropic reserve in moderately ischaemic myocardium at the expense of metabolic recovery: a model of short-term hibernation. Circ Res recovery: a mode

19 Cigarroa C, deFilippi CR, Brickner E, Alvarez L, Wait M, Grayburn P. Dobutamine stress echocardiography identifies hibernating myocardium and predicts recovery of left ventricular function after coronary revascularisation Circulation 1993;88:430-6.

20 Marzullo P, Parodi O, Reisenhofer B, et al. Value of rest thallium-201/technetium-99m sestamibi scans and dobutamine echocardiography for detecting myocardial viability. Am f Cardiol 1993;71:166-72.

21 Dilsizian V, Rocco TP, Freedman NMT, Leon MB, Bonow RO. Enhanced detection of ischemic but viable myocardium by the reinjection of thallium after stressredistribution studies. $N$ Engl f Med 1990;323:141-4.

22 Ragosta M, Beller GA, Watson DD, Kaul S, Gimple LW. Quantitative planar rest-redistribution ${ }^{201} \mathrm{Tl}$ imaging in detection of myocardial viability and prediction of improvement in left ventricular function after coronary improvement in left ventricular function after coronary ventricular function. Circulation 1993;87:1630-41.

23 Yang LD, Berman D, Maddahi J, et al. Late reversibility of tomographic myocardial thallium defects: an accurate marker of myocardial viability. $\mathcal{F} \mathrm{Am}$ Coll Cardiol 1988;12:1456-63.

24 Dilsizian V, Perrone-Filardi P, Arrighi JA, et al. Concordance and discordance between stressredistribution-reinjection and rest-redistribution thallium imaging for assessing viable myocardium. Circulation 1993;88:941-52.

25 Senior R, Sridhara BS, Raval U, Anagnostou E, Basu S, Lahiri A. Evaluation of rest Tl-201 SPECT protocols for the identification of viable myocardium [abstract]. Nucl Med Commun 1994;4:265.

26 Bodenheimer MM, Banka VS, Hermann GA, Trout RG, Pasdar H, Helfant R. Reversible asynergy: histopathologic and electrocardiographic correlations in patients logic and electrocardiographic correlations in patients

27 Senior R, Raval U, Lahiri A. Tc- $99 \mathrm{~m}$ sestamibi imaging reliably identifies retained contractile reserve in dysynerreliably identifies retained contractile reserve in
gic myocardial segments. $\mathcal{F}$ Nucl Cardiol In press.

28 Udelson J, Coleman P, Metherall J, et al. Predicting recovery of severe regional ventricular dysfunction. Comparison of resting scintigraphy with ${ }^{201} \mathrm{Tl}$ and ${ }^{99 \mathrm{~m}} \mathrm{Tc}$ sestamibi. Circulation 1994;89:2552-61.

29 Schulz R, Rose J, Martin C, Brodde OE, Heusch G. Development of short-term myocardial hibernation: its limitation by the severity of ischemia and inotropic stimulation. Circulation 1993;88:684-96.

30 Feigenbaum H. Exercise echocardiography. $f \mathrm{Am}$ Soc Echocardiogr 1988;1:161-6. 